A qualitative exploration of oncology nurses' family assessment practices in Denmark and Australia.

Corresponding author

Dr Elisabeth Coyne RN, RM, BN, MN (Hons), PhD

Senior Lecturer,

Menzies Health Institute

School of Nursing and Midwifery, Logan Campus, Griffith University, University Drive, Meadowbrook, Qld, 4131, Australia.

Email: e.coyne@griffith.edu.au

Karin B Dieperink PhD RN

Department of Oncology,

Odense University Hospital,

Southern Boulevard 29, DK-5000 Odense C, Denmark,

E-mail: karin.dieperink@rsyd.dk Phone: +45 21142404 


\section{A qualitative exploration of oncology nurses' family assessment practices in Denmark and Australia.}

\section{Background}

The nurses' ability to provide supportive care to the patient and family is influenced by their family assessment skills, which provides them with understanding of the family needs and strengths. When a patient is diagnosed with cancer it is the family who provide the long term support for the patient, and nurses need to understand the family needs in order to provide holistic care.

Objective: To understand the factors that influence nurses' family assessment practices in adult oncology setting in Denmark and Australia.

\section{Methods}

An interpretive qualitative study was conducted guided by Family Systems theory. Focus groups were completed with 62 nurses working in adult oncology areas in Denmark and Australia. A thematic analysis and computer generated concept mapping were completed to identify themes within the data.

\section{Results}

Overall the nurses valued family as part of the patient care and worked to understand the family concerns. However the family assessment process was unstructured, and did not enable holistic family support. Nurses from both countries discussed that experience and ability to engage with the family influenced the nurse's role in family assessment.

\section{Conclusion}

This study identified that nurses value family as part of patient care, however struggle to assess and support families during oncology care. There is a need for a structured assessment approach and education on family assessment, which could be used across the two countries and possibly internationally.

Nursing, oncology, family, supportive care, qualitative, international, family assessment, family nursing 


\section{Introduction}

When caring for an adult with cancer, nurses need to consider not only the patient, but also the multiple family members who are influenced by the diagnosis [1]. In order to provide care that is family centred the use of family assessment has been identified as being paramount to bringing the focus to the patient and family as a unit of care [2]. In Denmark and Australia adult nursing is predominantly 'patient in the centre' or a 'patient centred' approach, which may leave the family feeling like an outsider and not included with the care of the patient [3-5]. An important aspect of providing holistic care is recognising the principles of family-centred care, which include, but are not limited to, mutual respect, collaboration, and support for the patient and family [2]. To achieve collaboration and support of the family, an assessment of the family needs must be incorporated into the nurses' role to ensure that family-centred care is provided $[2,6]$. Family assessment provides a strategy to understand the needs of families, an opening to conversations, and enables the nurse to develop an understanding of the family's most critical and concerning challenges $[2,7]$.

\section{Literature review}

A cancer diagnosis is a stressful event for the family as they must adjust and adapt to the fluctuations in health from the disease and treatment. Forming the main support for the patient, the family members themselves often have complex needs, which often go unnoticed by the health professional $[1,8]$. The importance of family support when an adult has cancer has been strongly established, however, the provision of care is often patient centred $[9,10]$. American research exploring the family experience of oncology care, found that the relationship between the nurse and the family was strongly linked to more positive outcomes for the patient [1]. These findings highlights the importance of understanding the needs of the family when caring for a patient with cancer [11].

Exploring the supportive roles of typical families in Australia and Denmark has identified differences in gender roles, education and work hours for the family [12, 
13]. On average Australians were likely to work more hours and mothers were more likely to perform more child care responsibilities than in Denmark [12]. In Denmark, the role of parenting is shared often with grandparents, although this was not the case in Australia, where geographic location and isolation is an influence [12]. Australia also has a culturally diverse population with a predominately nuclear family situation with little extended family support which may explain the divergent parenting roles [14]. In Denmark, distances travelled are less and extended family is closer, hence different styles of family support [15].

In the Australian context, oncology care is predominately provided in an outpatient setting by registered nurses. In this setting, nurses provide education to the patient during scheduled treatment, and if time and space allows the family is present [16]. There are some specialist nurses, although there are often insufficient specialist nurses to provide expert patient and family-centred care $[17,18]$. Oncology care in Denmark is similar with the majority of care provided in the outpatient setting by registered nurses. The clinical areas are similar to Australia with few family friendly spaces to allow for family to interact with the nurses [19]. In Denmark, there are fewer specialist nurses available as noted by Danish nurses in the study.

Although nurses identify family support as an important aspect in the care of the patient, the actual care of the family is often difficult due to the nurses lack of confidence communicating and collaborating with the family [20, 21]. Another influencing factor is the nurses' past experience with both their own family and working with families. Seminal research by Wright and Bell [22] has highlighted the importance of the nurse understanding their own family perspective before entering into a conversation with the family. Education is considered to be a key aspect supporting the nurses' ability to seek opportunities for family assessment and in turn family support $[7,21,23]$.

Education about family nursing provides the registered nurse with the tools to conduct family assessment [7, 23, 24]. Family nursing is part of core content in some 
undergraduate nursing programs worldwide [25], with Canada and Iceland leading the way in educating nurses to the benefits of family assessment and intervention $[26,27]$. However, in Australia and Denmark, information about family nursing and family assessment is not a core component of most undergraduate curricula [28]. To influence and improve nurses' practice regarding family nursing, researchers must first understand the nurses' role and perception of family assessment and support as it is in present practice. The study reported in this paper explored how oncology nurses in Australia and Denmark conduct family assessment and what factors influence their engagement with the family.

\section{Method}

A qualitative approach using focus groups explored 62 registered nurses family assessment practices in adult oncology units in Australian and Denmark. The research was underpinned by the Family Systems Theory, which emphasizes the family as a unit and focuses on strengths and resources of the family [2, 29]. Focus group discussions were used to generate insights into the nurses' family assessment approaches and asked participants to consider the concept of family as a unit of care. [30].

\section{Procedure}

Registered nurses (RNs) working in adult oncology areas, including inpatient, day and radiation oncology from three hospitals in Queensland, Australia and one hospital in Odense, Denmark were invited to participate. Each hospital is a tertiary teaching hospital; however there are differences between each hospital's overall patient and family philosophy. A cross section of registered nurses from different areas was obtained to provide a broad view of the nurses' perspective of family assessment. Inclusion criteria was being a registered nurse, fluent in English and working in the oncology area. Recruitment was via information sessions and multiple focus groups times were organised to enhance participation [31].

Data were collected in late 2013 in Australia and subsequently in Denmark. A focus group guide was used (Table I) and the main researcher facilitated all focus groups in English; the other researcher took field notes, which were used to provide context 
in the thematic analysis. Focus group size differed in relation to the clinical area and the availability of nurses to complete the focus groups. Focus groups lasted 30-40 minutes, were audio taped and transcribed verbatim. During each focus group, participants were encouraged to share their thoughts, and opinions in an open table discussion.

Ethical approval was obtained from each participating hospital and Griffith University [GU Ref No: NRS/50/12/HREC]. The study was carried out in accordance to the principles of Helsinki declaration [32]. Written consent to participate was obtained; participants were informed of the aim of the study and that anonymity would be maintained. The researchers had previously worked in oncology areas and have completed previous studies exploring family needs. The researchers are experienced qualitative researchers.

Insert Table I

\section{Table I Focus group questions}

1. How do you as the nurse clarify with the patient who they include as their family support persons?

2. Can you explain what processes you use for family assessment?

3. How do you include the family members directly in the discussion and assessment?

4. In assessment of the patient and family needs, how do you include assessment of communication styles within the family unit?

5. In assessment of the patient and family needs, how do you include assessment of the family appraisal of the patient diagnosis?

6. In assessment of the patient and family needs, how do you include assessment of the way the family unit functions and works together to solve problems?

Data Analysis

Transcripts were analysed using inductive qualitative techniques that comprised a multi-phase thematic analysis [33, 34]. Both researchers highlighted key phases and 
grouped concepts into themes. A thematic table was constructed to see links between themes, and further redefining of themes occurred as patterns within the data became visible. Themes were discussed between the two researchers via skype and face to face, until consensus was reached. In keeping with the requirements for rigour and trustworthiness, the following steps were completed to enhance the reliability of the findings [35]. All focus group participants were offered the opportunity to review the transcripts and resultant themes, and were verified by five participants to be correct. An audit trail was created to document the process and reasoning behind the analysis decisions [36]. Results are presented in rich description to allow the reader to examine the transferability of the findings to other care settings and patient populations.

A secondary data analysis using Leximancer, a computer-assisted concept-mapping tool, was completed to provide validation of the themes [35, 37]. Leximancer software identifies phrases expressing a similar idea and groups them into clusters which can be used to support thematic analysis [38]. The researcher can tailor the program parameters to suit the data and the interactive conceptual map is presented with text matches and concept statistics [39]. Thesaurus settings were checked to ensure key words and linking words were present. Several concept maps were generated using the same settings to identity a consistent mapping of themes [40]. The ranked concept list and generated concept map supported the completed thematic analysis.

\section{Results}

Focus groups were conducted in Australia [20 focus groups $n=56$ ] and Denmark [2 focus groups $n=6$ ] with oncology nurses. Of the participants $91 \%$ were female and half of the participants were employed full-time. The mean age was 41 years and participants had worked in oncology nursing for a mean of 10 years. Bachelor degree was highest level for $51 \%$ of the participants. The nurses came from all three clinical areas with $47 \%$ working in day oncology. The main reason given for not participating was the inability to leave the clinical area for the focus groups. 
Insert Table II

Table II Demographic characteristics of oncology nurses

\begin{tabular}{|c|c|c|c|c|}
\hline$N=62$ & $\begin{array}{l}\text { Australia } \\
\mathrm{N}(\%)\end{array}$ & Denmark & & \\
\hline \multicolumn{5}{|l|}{ Gender } \\
\hline Female & $51(91)$ & $6(100)$ & & \\
\hline Male & $5(9)$ & 0 & & \\
\hline \multicolumn{5}{|l|}{$\begin{array}{l}\text { Highest } \\
\text { qualification }\end{array}$} \\
\hline $\begin{array}{r}\text { Bachelor of } \\
\text { Nursing }\end{array}$ & $32(51)$ & $6(100)$ & & \\
\hline $\begin{array}{l}\text { Graduate } \\
\text { certificate }\end{array}$ & $19(31)$ & & & \\
\hline Masters & $6(10)$ & & & \\
\hline Hospital certificate & $5(8)$ & & & \\
\hline \multicolumn{5}{|l|}{$\begin{array}{l}\text { Professional } \\
\text { membership }\end{array}$} \\
\hline None & $26(50)$ & $5(90)$ & & \\
\hline $\begin{array}{l}\text { Professional } \\
\text { Nurses } \\
\text { Association }\end{array}$ & $30(50)$ & $1(10)$ & & \\
\hline \multicolumn{5}{|l|}{ Work area } \\
\hline Inpatient & $19(30)$ & & & \\
\hline Day oncology & $25(47)$ & $4(70)$ & & \\
\hline \multirow{2}{*}{$\begin{array}{l}\text { Radiation } \\
\text { oncology }\end{array}$} & $12(23)$ & $2(30)$ & & \\
\hline & & 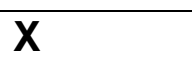 & SD & Range \\
\hline Age (years) & & 41 & 10 & $20-66$ \\
\hline Years as RN & & 16 & 10 & $1-48$ \\
\hline Years in oncology & & 10 & 7 & $1-29$ \\
\hline
\end{tabular}


The thematic analysis identified two themes which are presented in this paper. These themes were: understanding family assessment and doing family assessment.

\section{Understanding family assessment}

This theme related to the participants discussing their own experience and understanding of family assessment and how it influenced their response to the family. The participants' acknowledgement of their own family experience played a part in how they engaged with the family and utilised the time with the family. 'I know you need to use your experiences, but I think I look ahead instead. ... Who's helping you [patient]?' [DK]. These beliefs often directed how the nurses assessed the different family groups such as older patients, 'I'm very much alert about the old people, especially the single ones. I think they have special needs, the elderly patient, they have a sick wife or a sick husband' [DK]. Another aspect noted by both Australian and Danish participants was being aware of unspoken concerns between family members as part of their family assessment, 'they don't always tell each other how they really feel' [DK]; 'sometimes when you talk to them [the family] separately, you can tell it's not good at home' [AUS].

One of the Australian participants explained her strong focus on the family and how they supported the patient even extending this to external support persons: 'I actually ask them about their support team and if their family is part of that or if they're using outside of the family, because I also class outsiders who are doing that job as their family at the time, not just their blood. So they've got their own little oncology family I call it [AUS].'

The participants' personal connection to the family and their own feelings also influenced how they engaged with the family, 'How busy the ward is and how you feel with yourself. It depends on the nurse' [DK]. Australian participants also reported 'I think a lot of it is relied solely upon the nurse and their ability to assess patients and their family rather than having a tool to use' [AUS]. However, not all Australian participants had a strong belief in family assessment, 'don't see it [family assessment] as part of my role", and some focused on the patient, I am the 'the primary nurse for the patient' [AUS]. The Danish participants' comments reflected a 
family focus [a note of caution here is the small number of Danish nurses] 'I think it's a very important - key part for nurses' DK]. Although the nurses did acknowledge the difficulty of helping the family, "I think as a nurse it takes - you have to ask the questions as well because if the patients are getting sad and crying, you have to help them and sometimes it's easier not to ask' [DK]. Australian nurses also noted 'developing that therapeutic relationship that you need to do those kinds of assessments properly is difficult sometimes' [AUS].

\section{Doing family assessment}

The level of experience as a registered nurse was described by the participants as an influencing factor of family engagement and assessment. The participants from both countries commented on their own style of family assessment which they had developed with experience, 'I have a semi-structured system for myself so that I cover everything' [AUS]. Some of the participants called themselves experienced nurses and spoke of allowing the patient to talk 'l'll structure the interview to include review of the health history and then also a review of the appropriate education resources that they've been provided' [AUS]. These participants discussed gathering a range of information about the patient and family, but also how they clarified the family's use of resources. Overall the participants identified that prior experience was noted as an advantage for completing family assessment, particularly as their experience was often supported with education 'As a more experienced oncology nurse you do sense a little bit more with patients and family, ... it's not ad lib but it relies a lot on your rapport' [AUS]. Lack of experience was identified by the younger participants, 'guess just with the experience, I don't know what I'd do with that information' [AUS]. Danish participants' noted the similar problems, 'Some of us have been here for quite a few years and we have younger colleagues who have some doubt and I think it's probably more difficult for many of them' [DK]. While other Danish nurses explained about doing family assessment, 'it's not systematic education would help' [DK].

The allocation of nurses to the patients was different and this influenced how the participants established rapport with the patients, 'the model here is a collaborative model, so it's an oncologist with the registrar and then nurses assigned to that 
patient group' [AUS]. This model of care provided the participants with continuity of care for at least some of the time. Whereas in Denmark this was not the case 'We try to see the same patients, but it's very difficult. ... It is easier for the patient and for me if I can follow the patient' [DK]. The nurse was often relied upon for completion of the family assessment 'It's all medically orientated here so I do it [family assessment]' [AUS]. Although if the family had unmet needs identified by the nurse, their response often was that is not within their scope of practice, 'if they need extra care, like if they're just not coping we can refer them to social workers' [AUS]. However, in Denmark the social worker was not as readily available so the nurses tried to support the family 'Sometimes, if the patient has a problem, we can go deeper with support at the treatments' [DK]. This was an interesting point of difference between the two countries, as Australian participants identified that they would begin assessment but then refer to social worker and Danish participants described how they identified family problems and then aimed to provide time to sit and talk with the family.

Both Danish and Australian participants discussed documentation of family assessment; however there was no specific focus on family just general questions which may lead to family concerns. One Danish participant reported that 'we document it on their record. There is a space says, "Social Issues." "Psychosocial." [DK ]. In contrast the Australian comment about the assessment form was that, ' $I t$ [Family assessment] has a lot of clinical judgment ... It's [the document] an extra I can refer to, I certainly would not use it as a crutch; I want my own assessment.' This led to the participants discussing that family assessment 'could be done better, obviously, it just depends on skills of the interviewer or the nurse's training' [AUS]. Both Australian and Danish nurses responded that they like to interview with a plan, 'they love a piece of paper to guide them [the nurses] and some of us, I think, are just much more comfortable with our own style'.

\section{Leximancer analysis}

The secondary analysis was completed using Leximancer, which produced concepts that are comparable to the thematic analysis. The generation of concepts from all the transcripts enabled a diagrammatic view of the frequent words and how they linked 
and formed themes. The six concepts were nurse, family, talk, time, different and document. In the concept map the two concepts, nurse and family, were interlinked with asking questions, and doing family assessment. Similarly, in the thematic analysis these concepts related to how the nurse was able to do family assessment, and make the links to the patients' disease and family. The concept of talk in the concept map was central and included words such as home, information, cancer, work, need, people, support and care. This concept was in relation to how the nurse did family assessment. The concept of time was represented linked closely to talk. Time included words such as the social worker, feel and people, indicating that time was an influencing factor to the talk. In the thematic analysis, time was clearly evident as the nurses discussed the time aspect in relation to assessment. The concepts of different and document formed on the outside of the main concepts within the concept map with links to words such as cancer and work [different] and care and nurse [document]. These Leximancer themes support the researchers' thematic analysis. See Figure I for concept map. Insert Figure I

Figure I Leximancer generated concepts.

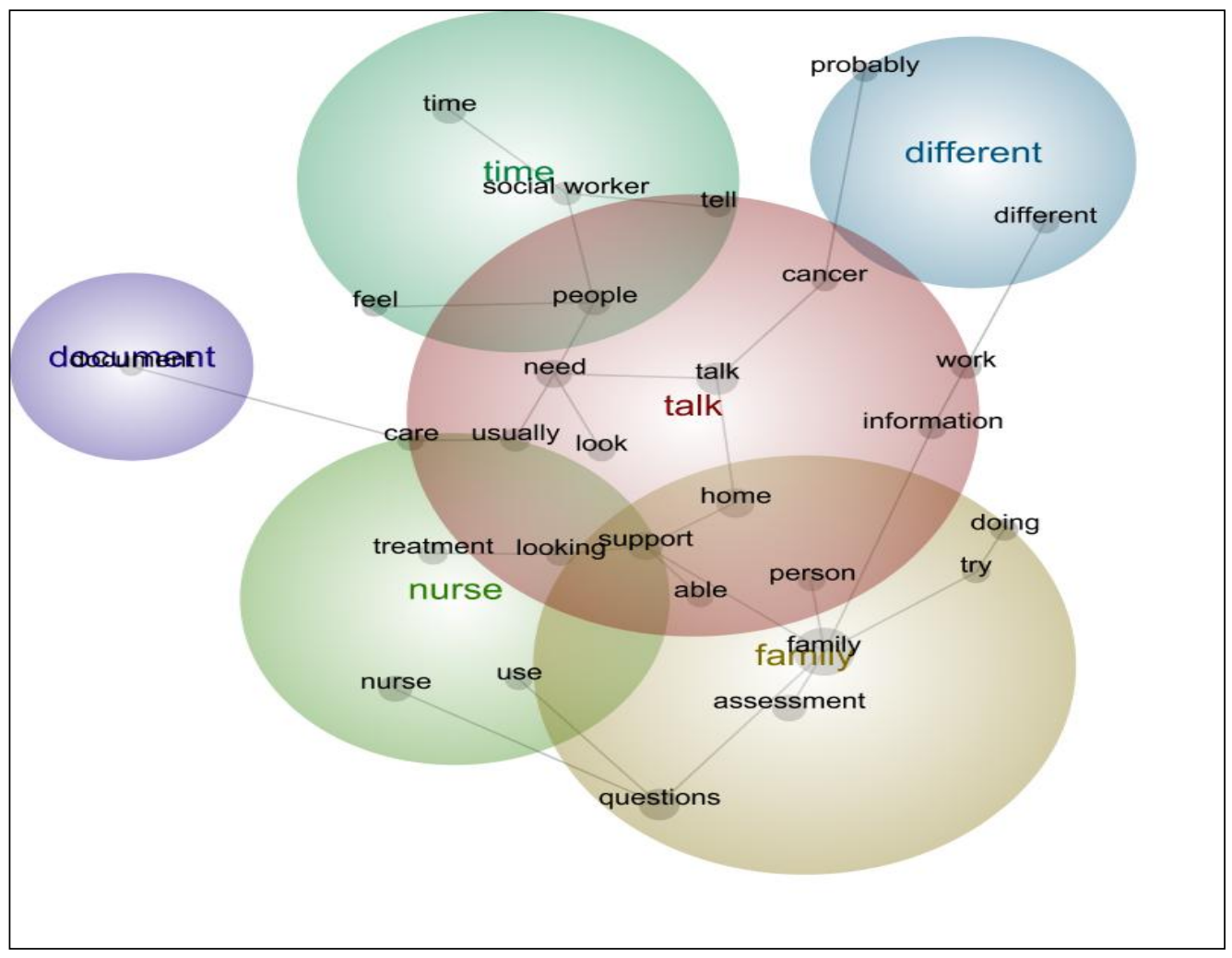




\section{Discussion}

This study sought to explore the oncology nurses' perspective of family assessment in Australia and Denmark. The study identified that the nurses valued family assessment and support; however, they do not always have the time or knowledge to understand and support the family. Through the analysis it became evident there were differences in the presence of family with the patient and this may have influenced how the nurse engaged with the family. The nurses discussed how to understand the family concerns, particularly when family were not always open or available. The participants talked about their roles and the time needed to support the family. Previous research has identified that time and also actual space for family engagement influenced the nurses' ability to assess and meet the family needs [21, $41,42]$.

In the present study, oncology nurses were open to engaging with the family, and discussed the value of family for supporting the patient. However, a clear sense of how the nurses assessed the family and made decisions on the need for extra support was not evident in the data. The participants' beliefs of what the family may need, often guided their engagement with the family. Several studies have explored the barriers and enablers for family engagement $[11,43]$. Consistent with the current research, barriers for providing supportive care related to being able to build a therapeutic relationship with the family. Beckstrand, Caollette [11] explored the barriers and enablers to family engagement in the palliative care setting and identified that the family acceptance, or not, of the diagnosis, influenced the nurses ability to build therapeutic conversation. The participants in the current study discussed that their personal beliefs as a nurse and their openness to engage with the family influenced the way they approached family assessment.

The building of a therapeutic relationship between the nurse, patient and family is a key to understanding and supporting the family. However this is linked to the nurses readiness to connect and ability to identify the underlying needs of the patient and family $[21,43]$. In the current study, the nurses described different approaches to understanding the family needs. In particular, the Danish participants spoke of 
grouping patients by diagnosis and completed assessment and care in relation to the nature of the cancer and side effects. Decision about care was often based on what the nurse perceived as the family needs. However, there were only a small number of participants $(n=6)$ in Denmark, but it does highlight the different way nurses connect with the patient. In contrast, some of the Australian participants explained how they were assigned to work with a medical team. This model of care meant that the nurses often cared for the same patients with similar cancers, allowing the nurses to approach the patient assessment with a sense of continuity of care. Although there was a connection with the patient, the nurses in Australia often used this rapport to refer the patient to a specialist team such as breast care nurses, cancer care coordinators or social workers. The family engagement was influenced by the nurses' perception of their own role and expertise. The literature identifies that nurses with access to training and resources demonstrate improved assessment and support of the family $[25,44]$. The provision of family-centred care and assessment is closely linked to the nurse developing a rapport with the family to understand the needs of the family $[5,45]$.

Increasing the nurses' understanding of family assessment and support will in turn improve their ability to provide holistic patient and family care $[11,19,21,43]$. All participants in the current study identified the need for education to provide a structure for assessment and family support. The benefit of education has been recognised by several family researchers, particularly through the use of a family assessment tool, which provides nurses with guidelines for recognising the family individuality and responding to their needs [11, 16, 23]. Previous research has identified that the more experienced nurse has the ability to be more reflective and responsive to the patient needs, often being able to understand the cancer experience from different perspectives as opposed to a task orientated position [43]. The nurses' ability to provide appropriate and supportive care that is both patient and family-centred allows for recognition of the individuality of the family and the strengths and resources they use to overcome adversity [21, 23].

\section{Limitations}


All the nurses involved had volunteered for the study, so they may have been more comfortable about sharing their family assessment experiences. However, the study did obtain a range of opinions from different levels of oncology nurses. Overall, this may limit the extent to which our findings are transferable. Although the study was completed in Australia and Denmark, a limitation of the Denmark contribution was the small number of Danish participants. However qualitative data was comparable to the Australia focus groups, thus analysis was completed, although with caution.

\section{Implications for nursing}

Recommendations from the findings would be to establish family assessment education to increase the nurses understanding of family assessment. Continued support such as in-service, posters and role modelling of family-centred care would sustain the nurses' family assessment practices. The need for family friendly space needs to be considered in the development of oncology units as this allows for interaction between the nurses and family.

\section{Conclusion}

This study identified that nurses in different settings and countries recognise the value of family, whilst acknowledging that they struggle to assess and provide appropriate family support. The participants identified a range of issues which they believe influenced their ability to complete family assessment and most saw themselves as a point for referral rather than tailoring supportive family care. The nurses' experience and their perception of time influenced their engagement with the family. The nurses generally had different approaches to family assessment and different styles of engaging with the patients from a diagnostic style to a collaborative style. 


\section{Reference List}

1. Northouse, L., A. Williams, M, B. Given, \& R. McCorkle, Psychosocial care for family caregivers of patients with cancer. Journal of clinical Oncology, 2012. 30(11): p. 1227-34. DOI: 10.1200/JCO.2011.39.5798

2. Wright, L., M \& M. Leahey, Nurses and Families: A guide to family assessment and intervention 6ed. 2013, Philadelphia: Davis Company.

3. Kean, S. \& M. Mitchell, How do intensive care nurses perceive families in intensive care? Insights from the United Kingdom and Australia. Journal of Clinical Nursing, 2014. 23(5-6): p. 663-672. DOI: 10.1111/jocn.12195.

4. Dieperink, K., B, L. Wagner, S. Hansen, \& O. Hansen, Embracing life after prostate cancer. A male perspective on treatment and rehabilitation European Journal of Cancer Care, 2013. DOI: 10.1111/ecc.12061.

5. Coyne, E., The strengths and resources used by families of young women with breast cancer. Australian Journal of Cancer Nursing, 2013. 14(2): p. 1016.

6. Coyne, I., Families and health-care professionals' perspectives and expectations of family-centred care: hidden expectations and unclear roles. Health Expectations, 2013: p. n/a-n/a. DOI: 10.1111/hex.12104.

7. Duhamel, F., F. Dupuis, \& L. Wright, Families' and Nurses' Responses to the "One Question Question": Reflections for Clinical Practice, Education, and Research in Family Nursing. Journal of Family Nursing, 2009. 15(4): p. 461485. DOI: 10.1177/1074840709350606.

8. Kim, Y., D. Kashy, A, R. Spillers, L, \& T. Evans, V, Needs assessment of family caregivers of cancer survivors: three cohorts comparsion. PsychoOncology, 2009. 19(6): p. 573-582. DOI: 10.1002/pon.1597.

9. Williams, A., M, A. Holmes Tisch, J. Dixon, K, \& R. McCorkle, Factors associated with depressive symptoms in cancer family caregivers of patients receiving chemotherapy. Supportive Care in Cancer, 2013. 21(9): p. 23872394. DOI: $10.1007 / \mathrm{s} 00520-013-1802-y$.

10. McLeod, D. L., D. M. Tapp, N. J. Moules, \& M. E. Campbell, Knowing the family: Interpretations of family nursing in oncology and palliative care. European Journal of Oncology Nursing, 2010. 14(2): p. 93-100. DOI: org/10.1016/j.ejon.2009.09.006.

11. Beckstrand, R., L, J. Caollette, L. Callister, \& K. Luthy, E, Oncology Nurses' Obstacles and Supportive Behaviors in End-of-Life Care: Providing Vital Family Care. Oncology Nursing Forum, 2012. 39(5): p. 398-406. DOI: 10.1188/12.ONF.E398-E406.

12. Craig, L. \& K. Mullan, Parenthood, Gender and Work-Family Time in the United States, Australia, Italy, France, and Denmark. Journal of Marriage and Family, 2010. 72(5): p. 1344-1361.

13. Rademakers, J., D. Delnoij, J. Nijman, \& D. de Boer, Educational inequalities in patient-centred care: patients' preferences and experiences. BMC Health Services Research, 2012. 12(1): p. 261.

14. AlHW. Australian Institute of Health and Welfare. 2015 [cited 2015 Oct 2015]; Available from: http://www.aihw.gov.aul.

15. Ostergaard, B. \& L. Wagner, The development of family nursing in denmark: current status and future perspectives. Journal of Family Nursing, 2014. 20(4): p. 487-500. DOI: 10.1177/1074840714557780. 
16. Coyne, E., E. Grafton, A. Reid, \& A. Marshall, Understanding family assessment in the Australian context; what are adult oncology nursing practices? Collegian, 2016. In Press. DOI: 10.1016/j.colegn.2016.01.001.

17. Liebert, B. \& S. Furber, Australian women's perceptions of a specialist breast nurse model. Australian Health Review, 2004. 27(2): p. 88-92.

18. Regan, M., J. Mills, \& E. Ristevski, Cancer care coordinators' relationships with the multidisciplinary team and patients: Everything to everyone. The Australian Journal of Cancer Nursing, 2012. 13(1): p. 12-19.

19. Dieperink, K. B., K. Mark, \& T. B. Mikkelsen, Marital rehabilitation after prostate cancer - a matter of intimacy. International Journal of Urological Nursing, 2016. 10(1): p. 21-29. DOI: 10.1111/ijun.12091.

20. Dougherty, M., Assessment of patient and family needs during an inpatient oncology experience. Clinical Journal of Oncology Nursing, 2009. 14(3): p. 301-306. DOI: 10.1188/10.CJON.301-306.

21. Coyne, I., M. Murphy, T. Costello, C. O'Neill, \& C. Donnellan, A Survey of Nurses' Practices and Perceptions of Family-Centered Care in Ireland. Journal of Family Nursing, 2013. 19(4): p. 469-488. DOI: $10.1177 / 1074840713508224$.

22. Wright, L., M \& J. Bell, M, Beliefs and Illness A model for healing. 2009, Canada: 4th Floor Press, INC

23. Ragnarsdóttir, A. \& E. K. Svavarsdottir, Advanced Knowledge in Nursing Practice can Make the Difference: The Value of a Nursing Intervention for Families of Children with Rare Chronic Illnesses. Vard i Norden, 2014. 34(1): p. 48-51.

24. Svavarsdottir, E. K., Listening to the Family's Voice: Nordic Nurses' Movement Toward Family Centered Care. Journal of Family Nursing, 2006. 12(4): p. 346-367. DOI: 10.1177/1074840706294536.

25. Braun, V., F \& C. Foster, Family Nursing: Walking the Talk. Nursing Forum, 2011. 46(1): p. 11-21. DOI: 10.1111/j.1744-6198.2010.00202.x.

26. Svavardottir, E., K, Excellence in Nursing A Model for Implementing Family Systems Nursing in Nursing Practice at an Institutional Level in Iceland. Journal of Family Nursing, 2008. 14(4). DOI: 10.1177/1074840708328123.

27. Duhamel, F., Implementing Family Nursing: How Do We Translate Knowledge Into Clinical Practice? Part II: The Evolution of 20 Years of Teaching, Research, and Practice to a Center of Excellence in Family Nursing. Journal of Family Nursing, 2010. 18(1): p. 8-25. DOI: 10.1177/1074840709360208.

28. Gill, F. J., G. D. Leslie, C. Grech, D. Boldy, \& J. M. Latour, Development of Australian clinical practice outcome standards for graduates of critical care nurse education. Journal of Clinical Nursing, 2014: p. n/a-n/a. DOI: 10.1111/jocn.12631.

29. Walsh, F., Strengthening Family Resilience. 2 ed. 2006, New York: The Guilford Press.

30. Doody, O., E. Slevin, \& L. Taggart, Focus group interviews in nursing research: part 1. British Journal of Nursing, 2012. 22(1).

31. Shaha, M., J. Wenzel, \& E. Hill, Planning and conducting focus group research with nurses. Nurse Researcher, 2011. 18(2): p. 77-87. DOI: 10.7748/nr2011.01.18.2.77.c8286. 
32. World Medical Association. World Medical Association Declaration of Helsinki 2008 [cited 2015 Nov ]; Available from: www.wma.net/en/30publications/10policies/b3/index.html.

33. Braun, V. \& V. Clarke, Using thematic analysis in psychology. Qualitative Research in Psychology, 2006. 3: p. 77-101.

34. Ryan, G., W \& H. Bernard, R, Techniques to identify themes. Field Methods, 2003. 15(1): p. 85-109. DOI: $10.1177 / 1525822 \times 02239569$.

35. O'Brien, B. C., I. B. Harris, T. J. Beckman, D. A. Reed, \& D. A. Cook, Standards for Reporting Qualitative Research: A Synthesis of Recommendations. Academic Medicine, 2014. 89(9): p. 1245-1251. DOI: 10.1097/ACM.0000000000000388.

36. Holloway, I. \& S. Wheeler, Qualitative research in nursing and healthcare. 3 ed. 2010, Malaysia: Wiley-Blackwell.

37. University of Queensland. Leximancer manual. 2014 [cited 2014 Nov ]; Available from: http://info.leximancer.com/.

38. Penn-Edwards, S., Computer Aided Phenomenography: The Role of Leximancer Computer Software in Phenomenographic Investigation. The Qualitative Report, 2010. 15(2): p. 252-267.

39. Cretchley, J., C. Gallois, H. Chenery, \& A. Smith, Conversations Between Carers and People With Schizophrenia: A Qualitative Analysis Using Leximancer. Qualitative health research, 2010. 20(12): p. 1611-1628. DOI: 10.1177/1049732310378297.

40. Moyle, W., L. Venturto, S. Griffiths, P. Grimbeek, M. McAllister, D. Oxlade, \& J. Murfield, Factors influencing quality of life for people with dementia: a qualitative perspective. Aging \& Mental Health, 2011. 15(8): p. 970-977.

41. Mitchell, M., W. Chaboyer, E. Burmeister, \& M. Foster, Positive effects of a nursing intervention on family-centered care in adult critical care. American Journal of Critical Care, 2009. 18(6): p. 543-552. DOI: 10.4037/ajcc2009226

42. Beck, S. A., J. Weis, G. Greisen, M. Andersen, \& V. Zoffmann, Room for family-centered care - a qualitative evaluation of a neonatal intensive care unit remodeling project. Journal of Neonatal Nursing, 2009. 15(3): p. 88-99. DOI: http://dx.doi.org/10.1016/j.jnn.2009.01.006.

43. Komatsu, H. \& K. Yagasaki, The Power of nursing: Guiding patients through a journey of uncertainty. European Journal of Oncology Nursing, 2014. 18(4): p. 419-424.

44. Botti, M., R. Endacott, R. Watts, J. Cairns, K. Lewis, \& A. Kenny, Barriers in Providing Psychosocial Support for Patients With Cancer. Cancer Nursing, 2006. 29(4): p. 309-316. DOI: 10.1097/00002820-200607000-00010.

45. Ernst, J. C., V. Beierlein, G. Romer, B. Möller, U. Koch, \& C. Bergelt, Use and need for psychosocial support in cancer patients. Cancer, 2013. 119(12): p. 2333-2341. DOI: 10.1002/cncr.28021. 